\title{
Flow cytogenetics and plant genome mapping
}

\author{
Jaroslav Doležel ${ }^{1}$, Marie Kubaláková ${ }^{1}$, Jan Bartoš $^{1}$ \& Jiř́ Macas ${ }^{2}$ \\ ${ }^{1}$ Laboratory of Molecular Cytogenetics and Cytometry, Institute of Experimental Botany, \\ Sokolovská 6, Olomouc, CZ-77200, Czech Republic; Tel: (+420) 585228 521; Fax: (+ 420$) 585228523$; \\ E-mail: dolezel@ueb.cas.cz; ${ }^{2}$ Laboratory of Molecular Cytogenetics, Institute of Plant \\ Molecular Biology, Branišovská 31, České Budějovice, CZ-37005, Czech Republic
}

Key words: chromosome-specific DNA libraries, chromosome sorting, flow cytometry, genomics, physical mapping

\begin{abstract}
The application of flow cytometry and sorting (flow cytogenetics) to plant chromosomes did not begin until the mid-1980s, having been delayed by difficulties in preparation of suspensions of intact chromosomes and discrimination of individual chromosome types. These problems have been overcome during the last ten years. So far, chromosome analysis and sorting has been reported in 17 species, including major legume and cereal crops. While chromosome classification by flow cytometry (flow karyotyping) may be used for quantitative detection of structural and numerical chromosome changes, chromosomes purified by flow sorting were found to be invaluable in a broad range of applications. These included physical mapping using PCR, high-resolution cytogenetic mapping using FISH and PRINS, production of recombinant DNA libraries, targeted isolation of markers, and protein analysis. A great potential is foreseen for the use of sorted chromosomes for construction of chromosome and chromosome-armspecific BAC libraries, targeted isolation of low-copy (genic) sequences, high-throughput physical mapping of ESTs and other DNA sequences by hybridization to DNA arrays, and global characterization of chromosomal proteins using approaches of proteomics. This paper provides a comprehensive review of the methodology and application of flow cytogenetics, and assesses its potential for plant genome analysis.
\end{abstract}

\section{Introduction}

Twenty years before the publication of this review, in March 1984, a paper by de Laat \& Blaas (1984) marked the beginning of plant flow cytogenetics. The authors described the preparation of a suspension of intact chromosomes from a model plant, Haplopappus gracilis $(2 n=4)$, and the separation of its two chromosome types by flow cytometry. At this time, flow cytogenetics was still a young science, but was already having a notable impact on human genetics, and showing the first promising results in farm animals (Van Dilla et al. 1986, Grunwald et al. 1989).

Flow cytogenetics is the use of flow cytometry and sorting for classification and purification of chromosomes isolated from mitotic cells (Carrano et al. 1983). The analysis is based on the ordered flow of metaphase chromosomes at high speed in a narrow liquid stream through a beam of intense light. Pulses of scattered light and 
fluorescence of stained chromosomes are quantified, and the analysis (called flow karyotyping) facilitates classification of large populations of chromosomes according to their size, morphology and relative fluorescence intensity. Individual chromosomes may be purified at high speed by breaking the liquid stream into droplets and deflecting electrically charged droplets containing chromosomes of interest by a passage through an electrostatic field (Givan 2001).

Hopes that flow karyotyping could be used for automatic detection of numerical and structural chromosome aberrations in humans (Boschman et al. 1992) have remained largely unfulfilled. On the other hand, flow cytometric sorting turned out to be invaluable for the purification of large quantities of wild-type and aberrant chromosomes whose DNA could be used in applications such as physical gene mapping, isolation of molecular markers, preparation of painting probes, and construction of chromosome-specific DNA libraries. Up to the present, there has been no substitute for flow cytometry when large quantities of chromosomes are needed and/or preparation of high-molecular-weight DNA is required.

These applications appeared to be attractive to plant geneticists. Compared with Arabidopsis and rice, the two plant species whose genomes have been sequenced, most crop plants possess much larger genomes whose size is many times greater than that of the human genome. In addition, the polyploid nature of many crops represents an obstacle to their analysis. Fractionation of their genomes into defined parts, such as chromosomes and chromosome arms, could facilitate gene mapping and cloning. However, as in many other cases, plant cytogenetics had to struggle with characteristics inherent in plants, and methods developed for humans and animals were not easily transferable to plants. The two main problems were the preparation of suspensions of intact chromosomes and the discrimination of individual chromosome types, a prerequisite for their sorting (Doležel et al. 1994). The purpose of this paper is to review the twenty years of development of plant flow cytogenetics, the applications of flowsorted plant chromosomes, and to assess the potential and prospects of flow cytogenetics for plant genome mapping.

\section{Methodology}

The procedure for chromosome analysis and sorting using flow cytometry consists of cell cycle synchronization and accumulation of mitotic cells in metaphase, preparation of chromosome suspensions, and their analysis and sorting (Doležel et al. 1999b).

\section{Choice of material}

Three biological systems were considered as sources of plant chromosomes for flow cytometry. Suspension-cultured cells appeared attractive as large populations of cells could be easily manipulated. This was the system used by de Laat \& Blaas (1984) and subsequently also by Arumuganathan et al. (1991) and Wang et al. (1992) to isolate chromosomes of tomato and wheat. The fact that the cultures may be heterogeneous (Arumuganathan et al. 1991), karyologically unstable (Leitch et al. 1993, Schwarzacher et al. 1997), and may be difficult to initiate in other species, stimulated a search for other experimental systems. A French group pioneered the use of leaf mesophyll protoplasts (Conia et al. 1987, 1989). As the frequency of metaphase cells was rather low, and because, for many plant species, protoplast culture is unsuccessful or unreliable, this system has not been used further. In 1992, Doležel et al. (1992) showed that suspensions of intact chromosomes could be prepared from root tip meristems, which are karyologically stable. This system has been universally accepted as it may be easily modified for use with various species (Table 1). The use of genetically transformed 'hairy' root cultures is an option when specific cytogenetic stocks cannot be propagated sexually (Veuskens et al. 1995, Neumann et al. 1998).

\section{Induction of mitotic synchrony}

Suspension-cultured cells could be synchronized by nutrient starvation and transfer to fresh medium (Arumuganathan et al. 1991). Similarly, a transfer to culture medium induced synchronous division of leaf mesophyll protoplasts (Conia et al. 1987, 1989). As the degree of synchrony depends critically on the state of the cultured 
Table 1. List of plant species from which flow cytometric analysis of mitotic chromosomes has been reported.

\begin{tabular}{|c|c|c|c|c|c|}
\hline \multirow[b]{2}{*}{ Species } & \multirow[b]{2}{*}{ Material } & \multirow[b]{2}{*}{$n^{*}$} & \multicolumn{2}{|c|}{$\begin{array}{l}\text { Number of discriminated } \\
\text { chromosomes }\end{array}$} & \multirow[b]{2}{*}{ References } \\
\hline & & & $\begin{array}{c}\text { Standard } \\
\text { karyotype** }\end{array}$ & $\begin{array}{l}\text { Cytogenetic } \\
\text { stock }^{* * *}\end{array}$ & \\
\hline Avena sativa & Root meristems & 21 & 0 & $1^{\mathrm{a}}$ & Li et al. (2001) \\
\hline Cicer arietinum & Root meristems & 8 & 5 & - & Vláčilová et al. (2002) \\
\hline Haplopappus gracilis & Suspension cells & 2 & 2 & - & $\begin{array}{l}\text { de Laat \& Blaas (1984), } \\
\text { de Laat \& Schel (1986) }\end{array}$ \\
\hline Hordeum vulgare & Root meristems & 7 & 1(2) & 3 & Lysák et al. (1999), Lee et al. (2000) \\
\hline Lycopersicon esculentum & Suspension cells & 12 & 0 & - & Arumuganathan et al. (1991) \\
\hline Lycopersicon pennellii & Suspension cells & 12 & 2 & - & Arumuganathan et al. $(1991,1994)$ \\
\hline Melandrium album & Hairy root meristems & 12 & 2 & - & Veuskens et al. (1995), Kejnovskỳ et al. (2001) \\
\hline $\begin{array}{l}\text { Nicotiana } \\
\text { plumbaginifolia }\end{array}$ & Mesophyll protoplasts & 10 & 0 & - & Conia et al. (1989) \\
\hline Oryza sativa & Root meristems & 12 & 0 & - & Lee \& Arumuganathan (1999) \\
\hline Petunia hybrida & Mesophyll protoplasts & 7 & 1 & - & Conia et al. (1987) \\
\hline Picea abies & Root meristems & 12 & 3 & - & Überall et al. (2003) \\
\hline \multirow[t]{2}{*}{ Pisum sativum } & Root meristems & 7 & 2 & 4 & Gualberti et al. (1996), Neumann et al. (2002) \\
\hline & Hairy root meristems & 7 & 2 & 4 & Neumann et al. (1998) \\
\hline Secale cereale & Root meristems & 7 & 1 & $2^{\mathrm{b}}$ & Kubaláková et al. (2003a) \\
\hline \multirow[t]{2}{*}{ Triticum aestivum } & Suspension cells & 21 & 0 & - & Wang et al. (1992), Schwarzacher et al. (1997) \\
\hline & Root meristems & 21 & $1(2)$ & $2^{c}$ & $\begin{array}{l}\text { Lee et al. (1997), Gill et al. (1999), } \\
\quad \text { Vrána et al. (2000), Kubaláková et al. (2002) }\end{array}$ \\
\hline Triticum durum & Root meristems & 14 & 0 & $2^{\mathrm{d}}$ & Kubaláková et al. (2003b) \\
\hline Vicia faba & Root meristems & 6 & 1 & 6 & Lucretti et al. (1993), Doleel \& Lucretti (1995) \\
\hline Zea mays & Root meristems & 10 & 2(3) & - & Lee et al. $(1996,2002)$ \\
\hline
\end{tabular}

*Number of chromosomes in a haploid set. ${ }^{* *}$ Number of chromosomes that could be discriminated unambiguously. The numbers in brackets indicate the number of chromosomes that could be discriminated in some lines due to chromosome polymorphism. ${ }^{* * *}$ Maximum number of chromosomes discriminated in one line. Different chromosomes may be discriminated by a judicious choice of specific

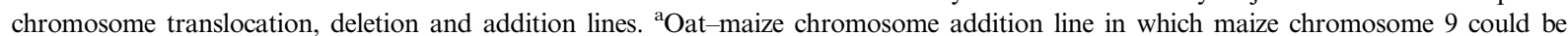
discriminated ( $\mathrm{Li}$ et al. 2001). ${ }^{\mathrm{b}} \mathrm{Rye}$ chromosomes $2 \mathrm{R}-7 \mathrm{R}$ could be discriminated from wheat-rye chromosome addition lines (Kubaláková et al. 2003a). "Sorting of almost all chromosome arms is possible in hexaploid wheat using individual (di)telosomic lines (Kubaláková et al. 2002). ${ }^{\mathrm{d} A l l}$ chromosome arms may be sorted from individual (di)telosomic lines (Kubaláková et al. 2003b).

cells, approaches based on the use of DNA synthesis inhibitors have been preferred (de Laat \& Blaas 1984, Wang et al. 1992). The inhibitors accumulate cycling cells at the $\mathrm{G}_{1} / \mathrm{S}$ interface, and, upon release from the block, the cells transit $\mathrm{S}$ and $\mathrm{G}_{2}$ phases and enter mitosis synchronously (Doležel et al. 1999a). This approach has been used to synchronize root meristems, resulting in mitotic indices of 45-62\% (Doležel et al. 1992, Kubaláková et al. 2003a), with lower values for hairy root cultures (Neumann et al. 1998). Hydroxyurea and aphidicolin were the only two inhibitors used, the former being cheaper and far more popular. Although the use of hydroxyurea was questioned due to its potential for inducing chromosome breakage (Eriksson 1966), de Laat $\&$ Schel (1986) were unable to detect any damage to sorted chromosomes of $\mathrm{H}$. gracilis. This was recently confirmed by $\mathrm{Li} \&$ Arumuganathan (2000) and Šimková et al. (2003) who recovered intact DNA from flow-sorted chromosomes in various species, although these studies could not exclude the presence of breaks in chromosomal DNA.

\section{Accumulation of mitotic cells in metaphase}

Provided the cells enter mitosis synchronously, they may be accumulated in metaphase by the action of mitotic spindle inhibitors. The alkaloid 
colchicine was the first to be used (de Latt \& Blaas 1984, Conia et al. 1987). However, as its affinity to plant tubulins is rather low, and it is effective only in millimolar concentrations, it has been replaced by synthetic herbicides such as amiprophos-methyl (Doležel et al. 1992), oryzalin (Veuskens et al. 1995) and trifluralin (Lee et al. 1996), which are effective at micromolar concentrations. Although the number of cells accumulated at metaphase is related to the duration of the treatment, short metaphase block has been preferred to avoid chromosomes splitting into chromatids, and to prevent chromosome decondensation (Doležel et al. 1992, 1994). The frequency of chromosome clumps may be further reduced by incubation in ice-cold water following treatment with the spindle inhibitor (Lysák et al. 1999). Optimised protocols result in accumulation of more than $50 \%$ of cells in metaphase (Lee et al. 1996, 1997, Vláćilová et al. 2002, Kubaláková et al. 2003a), a level considered critical for preparation of high-quality chromosome suspensions (Doležel et al. 1999b).

\section{Preparation of chromosome suspensions}

Release of chromosomes from plant cells is hampered by the presence of the rigid cell wall. Early studies used hydrolytic enzymes to remove the cell wall, and chromosomes were released after the lysis of protoplasts in a hypotonic buffer (de Laat \& Blaas 1984, Arumuganathan et al. 1991, Wang et al. 1992, Veuskens et al. 1995). The problem with this approach was that chromosome decondensation occurred during the prolonged incubations in hydrolytic enzymes. In order to release chromosomes from root tips, Doležel et al. (1992) developed a novel procedure in which chromosomes are released from formaldehydefixed tissues by chopping with a scalpel. Subsequently, a mechanical homogenizer has been used (Gualberti et al. 1996). This rapid and now almost generally used method avoids long treatments with enzymes which may be contaminated by DNases. Lee et al. (1996) introduced a modified version of the protocol which omits the fixation step. However, the formaldehyde fixation makes chromosomes more resistant to mechanical shearing forces during flow sorting, and re-sorting of sorted fractions is possible to achieve high purities (Lucretti et al. 1993). Various buffers have been used to isolate plant chromosomes (Doležel et al. 1994), the most frequent being the polyamine-based buffer LB01 (Doležel et al. 1989) and a magnesium sulphate-based buffer (Lee et al. 1996). Reported chromosome concentrations ranged from $1.6 \times 10^{5}$ to $1 \times 10^{6}$ per $\mathrm{ml}$ of a sample (Gill et al. 1999, Doležel et al. 1992).

\section{Flow karyotyping and discrimination of single chromosome types}

Traditionally, chromosome suspensions are stained by one or two DNA fluorochromes, and distributions of relative fluorescence intensity are displayed as monoparametric and biparametric flow karyotypes, respectively (Gray \& Cram 1990). Ideally, each chromosome is discriminated as a well-separated peak. Unfortunately, this is rare in plants due to the absence of significant differences in DNA content among chromosomes, and usually only one or few chromosomes can be discriminated (Table 1, Figure 1a). The failure of bivariate flow karyotyping in plants, which relies on simultaneous staining with AT- and GCspecific dyes to facilitate chromosome discrimination on the basis of DNA composition, is most probably due to homogenously dispersed repetitive DNA sequences (Lucretti \& Doležel 1997, Lee et al. 1997, 2000). Despite some promising results with the labelling of specific repetitive sequences on chromosomes in suspension (Pich et al. 1995, Macas et al. 1995), this approach has never become routine as it is hard to achieve quantitative labelling (Doležel et al. unpublished).

The recent progress in plant flow cytogenetics has been stimulated by a judicious use of cytogenetic stocks. Lucretti et al. (1993) and Doležel \& Lucretti (1995) showed that field bean chromosomes whose length has been altered by translocation could easily be discriminated (Figure 1b). Since then, a whole range of cytogenetic stocks, including deletions, translocation and chromosome additions, has been found useful to discriminate specific chromosomes and chromosome arms in a variety of species (Table 1 Gill et al. 1999, Li et al. 2001, Kubaláková et al. 2002, 2003a, 2003b). Simulated flow karyotypes have been employed to 


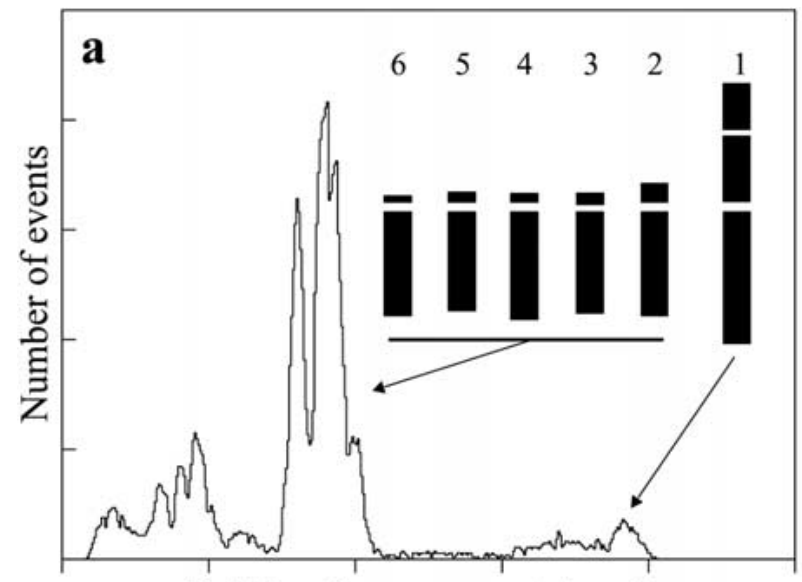

Relative fluorescence intensity

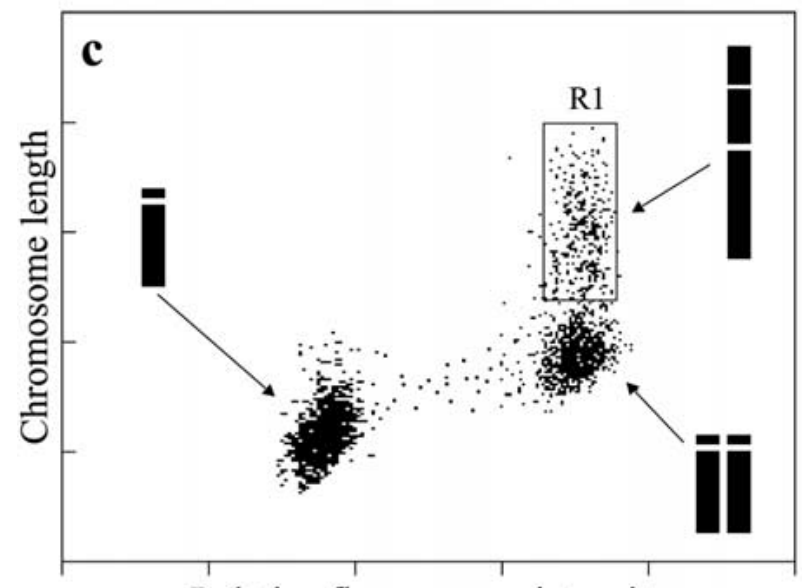

\section{Relative fluorescence intensity}

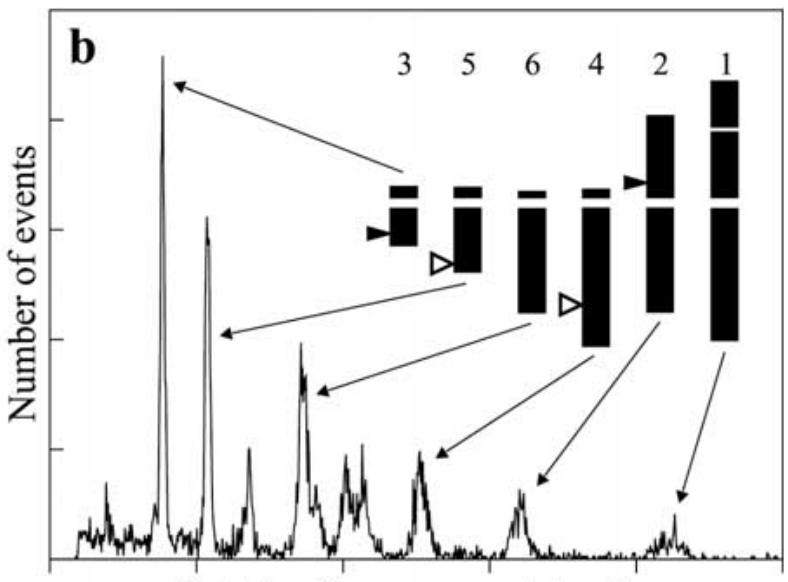

Relative fluorescence intensity

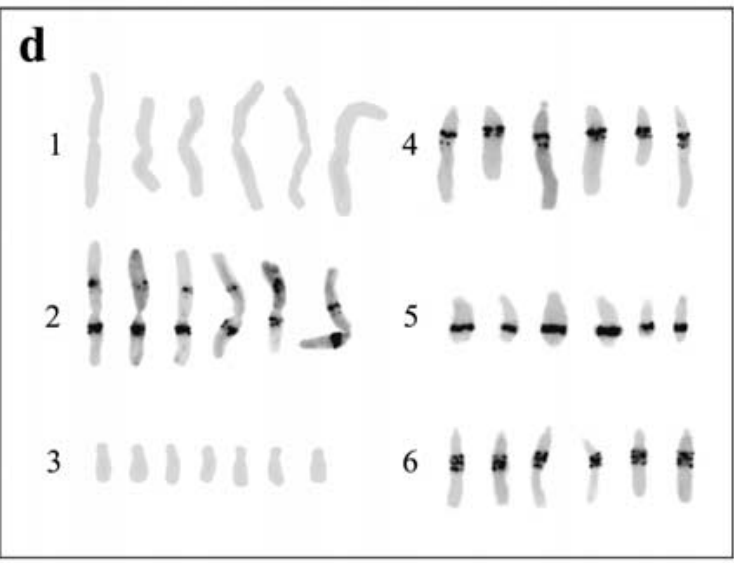

Figure 1. Chromosome analysis and sorting in field bean (Vicia faba, $2 n=12$ ). (a) Flow karyotype of cv. Inovec with wild-type chromosomes. Five acrocentric chromosomes (2-6) have similar size, and form a composite peak. Only the largest metacentric chromosome 1 can be discriminated and sorted. (b) Flow karyotype of a translocation line EF, whose chromosomes differ in size due to two reciprocal translocations (breakpoints marked by arrowheads). All six chromosomes are discriminated as well-separated peaks and may be sorted. Non-labelled peaks represent chromatids and chromosome arms. (c) Dot-plot of fluorescence intensity versus chromosome length obtained in cv. Inovec. Fluorescence intensity of doublets of acrocentric chromosomes is similar to that of the large metacentric chromosome 1, and the chromosome may be sorted at high purity by choosing a sort window (R1), which avoids the doublets (Lucretti et al. 1993). (d) Examples of chromosomes sorted from line EF; note the variation in length. The chromosomes can be identified unambiguously after fluorescent labelling of the FokI repeat using PRINS (Doležel et al. 1999b). The colour image was converted to grey scale.

predict a feasibility of discriminating individual chromosome types depending on differences in relative DNA content and on the coefficient of variation of the chromosome peaks (Lysák et al. 1999, Lee et al. 2002). The karyotypes were modelled using computer spreadsheet software (Conia et al. 1989) or a dedicated computer program (Doležel 1991) based on relative chromosome length or relative chromosomal DNA content.

\section{Chromosome sorting}

Any chromosome or group of chromosomes that can be discriminated on a flow karyotype can be sorted (Figure 1a, b, d). Plant chromosomes have been sorted onto nylon filters, microscope slides, and into PCR and other tubes (de Laat \& Blass 1984, Conia et al. 1987, Arumuganthan et al. 1994). Compared with humans and animals, plant 
chromosome suspensions are less concentrated and the sorting speed with conventional flowsorters ranged from 5 to 80 chromosomes/s (de Laat \& Blaas 1984, Lysák et al. 1999). Although the sorting rate might be increased using highspeed sorters, a low sample density will remain a limiting factor. During a large-scale chromosomesorting experiment, Šafár et al. (2003) were able to sort $2 \times 10^{5}$ wheat chromosomes during one working day. Sorting of millions of chromosomes is therefore possible but represents a major exercise. On the other hand, sorting of hundreds or thousands of chromosomes is easy.

The usefulness of flow-sorted fractions depends on the extent of contamination with other chromosomes and their parts, which may be determined microscopically (de Laat \& Blass 1984). However, as the chromosome morphology may be changed after sorting, molecular cytogenetic techniques including fluorescence in-situ hybridization (FISH) and primed in-situ DNA labelling (PRINS) have been preferred (Kubaláková et al. 2000, Li et al. 2001; Kubaláková 2003a, Figure 1d). Dot-blotting and, more frequently, PCR with specific primers have also been used (Arumuganathan et al. 1994, Lysák et al. 1999, Vrána et al. 2000) but are not suitable for determining the frequency of individual contaminants (Kubaláková et al. 2000). In some cases, the purity in sorted chromosome fractions has reached 100\% (Lysák et al. 1999, Vrána et al. 2000, Vláčilová et al. 2002). The purity was found to depend on the degree of resolution of individual chromosomes, and the presence of particles and clusters of particles with the same DNA content as the sorted chromosome (Doležel et al. 2001). The purity may be improved by appropriate gating to select a subpopulation of particles for further signal processing, and by properly setting a sort window which defines the sorted population. Conia et al. (1987) found that discrimination of Petunia chromosomes could be improved by simultaneous analysis of forward-angle light scatter and relative DNA content. Lucretti et al. (1993) showed that a sort window selecting particles based on relative fluorescence intensity and length improved the purity in a sorted fraction of field bean chromosomes (Figure 1c). They also demonstrated that twostage sorting reduced contamination with doublets of chromosomes whose length is similar, as the doublets were dissociated during the first sort run.

\section{Applications}

\section{Flow karyotyping}

Doležel et al. (1994) reasoned that flow karyotyping should be sensitive enough to detect numerical and structural chromosome changes in plants, including chromosome polymorphism. During the last decade, these predictions have been fulfilled. The ability to detect numerical chromosome changes was demonstrated in barley, where trisomy of chromosome 6 could be identified easily (Lee et al. 2000). The presence of an alien chromosome was detected in an oatmaize addition line ( $\mathrm{Li}$ et al. 2001) and in six different wheat-rye addition lines, where flow karyotyping also permitted monitoring the frequency of alien chromosomes in the population (Kubaláková et al. 2003a; Figure 2a, b). The ability to recognise chromosome translocations and deletions has been documented in field bean, garden pea, barley, rye and wheat (Doležel \& Lucretti 1995, Neumann et al. 1998, Gill et al. 1999, Lysák et al. 1999, Vrána et al. 2000, Kubaláková et al. 2002, 2003a; Figure 2c, d). By flow karyotyping, Kubaláková et al. (2002) discovered a translocation chromosome $5 \mathrm{BL} \cdot 7 \mathrm{BL}$ in seven wheat cultivars where its presence was not known before (Figure 2c). In wheat cultivars 'Panthus' and 'Sida' they identified a chromosome 4D, whose length had increased due to an unknown duplication or translocation. Finally, Kubaláková et al. (2003a) discovered B chromosomes in a rye cultivar 'Adams' (Figure 2e, f).

Generally, chromosomes are only detected if their size has been changed so that they differ enough from the remaining chromosomes. However, the case of the $1 \mathrm{BL} \cdot 1 \mathrm{RS}$ translocation in wheat shows that even a poorly discriminated chromosome may be detected by a characteristic change in the flow karyotype (Kubaláková et al. 2002). Chromosome deletions have also been identified in wheat using flow karyotyping (Gill et al. 1999, Kubaláková et al. 2002). Furthermore, flow karyotyping was found to be sensitive enough to detect polymorphism in relative DNA content of chromosomes in wheat, rye, maize and barley, and the 'fingerprint' patterns of flow karyotypes characteristic for certain cultivars are heritable (Lee et al. 2000, 2002, Kubaláková et al. 2002, 


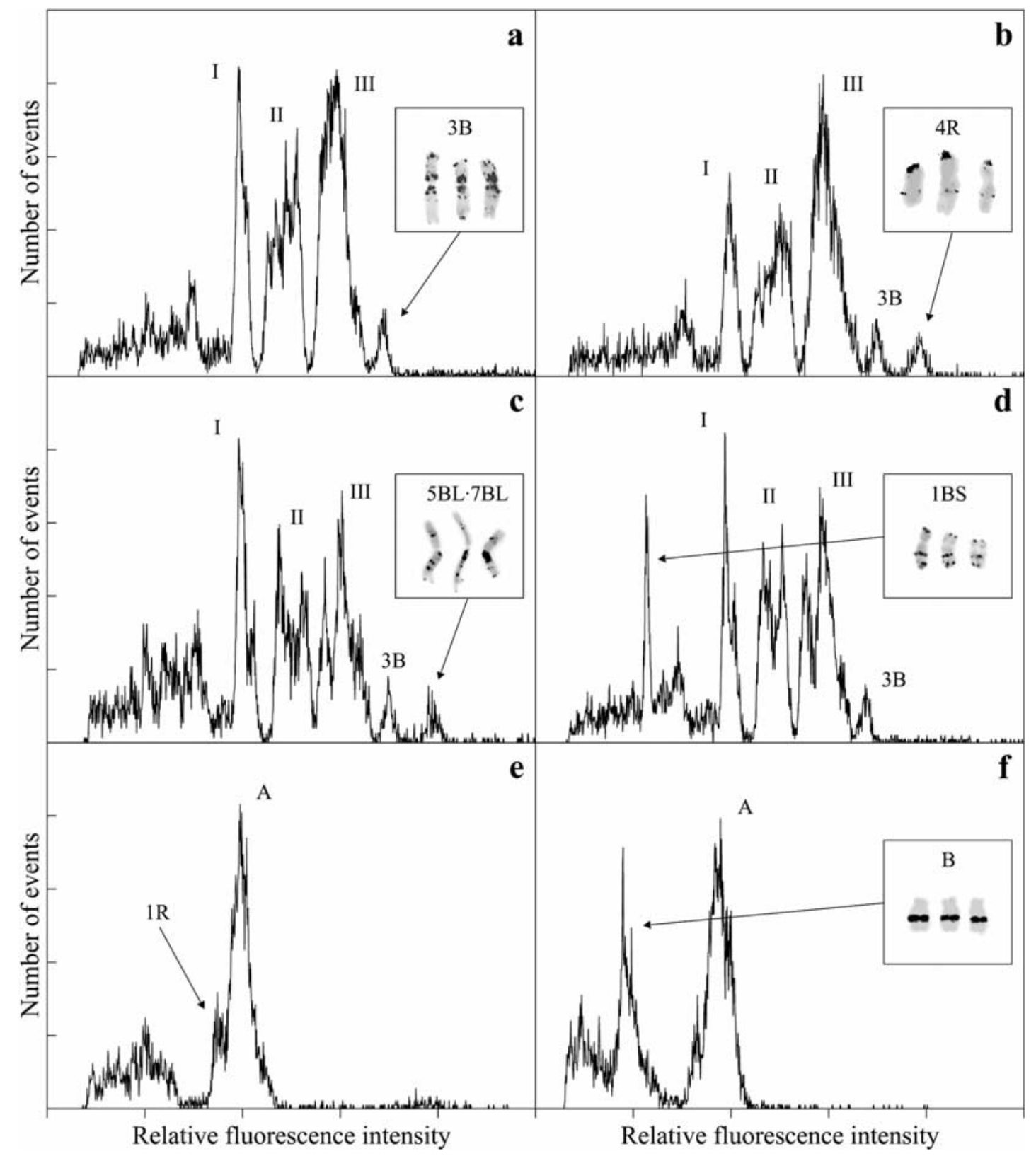

Figure 2. Chromosome analysis and sorting in cereals. (a) Flow karyotype of wheat (Triticum aestivum, $2 n=6 x=42) \mathrm{cv}$. Chinese Spring. Only chromosome 3B can be discriminated and sorted. Remaining chromosomes form three composite peaks (I-III). (b) Identification of a rye chromosome $4 \mathrm{R}$ on a flow karyotype of a wheat-rye chromosome addition line. (c) Discovery of a translocation chromosome 5BL-7BL in wheat cv. Famulus. (d) Flow karyotype of a ditelosomic line of wheat showing a well-discriminated peak containing the short arm of chromosome 1B (1BS). (e) Flow karyotype of rye (Secale cereale, $2 n=14) \mathrm{cv}$. Selgo. All seven chromosomes form a composite peak (A) with a shoulder containing chromosome 1R. No chromosome can be sorted at high purity from this variety. (f) Discovery of supernumerary B chromosomes in rye cv. Adams. Inserts: examples of sorted chromosomes after fluorescent labelling of GAA microsatellites (a, c, d) using PRINS (Kubaláková et al. 2002), and repeated sequences pSc119 (b) and Afa (f) using FISH (Kubaláková et al. 2003a). Colour images were converted to grey scale. 
2003a). It should be noted that the currently used protocols require a large number of root tips to prepare chromosome suspensions. However, Gualberti et al. (1996) demonstrated that a chromosome suspension could be prepared from a single root, demonstrating the possibility of analysing chromosomes of individual plants.

\section{Chromosome sorting}

Although chromosomal DNA is the obvious target, isolated plant chromosomes were found to be suitable for ultrastructural analysis using scanning electron microscopy, and for protein analysis. Compared with other protocols (Wanner et al. 1991), large numbers of chromosomes may be prepared, they are not covered by remnants of cytoplasm, and their morphology is well maintained (Schubert et al. 1993). The same authors showed that, for the same reasons, isolated chromosomes were an ideal target for immunolocalization of proteins. This opportunity was explored by Binarová et al. (1998) to demonstrate $\gamma$-tubulin in the kinetochore/centromeric regions of plant mitotic chromosomes. Subsequently, ten Hoopen et al. (2000) used flowsorted field bean and barley chromosomes in a detailed study on plant kinetochore proteins.

Lucretti et al. (1993) and Gualberti et al. (1996) showed that chromosomes sorted onto microscope slides were suitable for localization of DNA sequences using FISH and PRINS, respectively. In these studies, and in many others that followed, FISH and PRINS were used to identify flow-sorted chromosomes (Lysák et al. 1999, Vrána et al. 2000, Neumann et al. 2002, Vláćilová et al. 2002, Kubaláková et al. 2003a, 2003b). Compared with conventionally prepared metaphase spreads, sorted chromosomes appear to be an attractive target for FISH and PRINS, as they are completely free of cytoplasmic contamination and thus facilitate high-resolution physical cytogenetic mapping. As thousands of chromosomes may be analysed on one slide, screening of large chromosome populations is feasible. For example, the analysis of one thousand sorted chromosomes is equivalent to screening five hundred metaphase plates. This approach facilitated the analysis of the intravarietal polymorphism in genomic distribution of GAA clusters in wheat
(Kubaláková et al. 2002), and the identification of a rare translocation between $\mathrm{A}$ and $\mathrm{B}$ chromosomes in rye (Kubaláková et al. 2003a; Figure 3a). The power of FISH on flow-sorted chromosomes has been greatly increased since a protocol for preparation of super-stretched chromosomes was developed (Valárik et al. 2003). Sorted chromosomes may be elongated up to a hundred fold compared with untreated chromosomes, making them outstanding material for high-resolution physical mapping (Figure 3c). The technique is especially attractive for plant species with large genomes as an alternative to FISH on pachytene chromosomes, which are generally too long to trace individually (de Jong JH et al. 1999).

The most frequent use of flow-sorted human and animal chromosomes has been the preparation of chromosome painting probes from chromosome libraries (Cremer et al. 1988, Pinkel et al. 1988) or from small numbers of sorted chromosomes after PCR amplification and DNA labelling (Telenius et al. 1992). Despite great efforts, attempts to paint plant chromosomes using probes prepared from flow-sorted chromosomes have failed. Presumably, because of the presence of large amounts of homogenously dispersed repetitive DNA sequences in plant genomes, the painting probes prepared so far hybridized to all chromosomes within a set (Schubert et al. 2003).

An attractive application of flow-sorted chromosomes is physical mapping of DNA sequences using dot blotting and PCR. In order to assign individual chromosomes to peaks on the flow karyotype, Arumuganathan et al. (1994) sorted tomato chromosomes from well-resolved peaks onto membrane filters and used them for hybridization with chromosome-specific repetitive DNA probes. As this method requires ten thousand chromosomes to be sorted for each spot, which is time-consuming, it has never been used for mapping. On the other hand, only hundreds of chromosomes are sufficient for PCR with sequence-specific primers. As sorting of hundreds of chromosomes takes only a few minutes, large screening panels may be prepared for highthroughput mapping using PCR.

Macas et al. (1993) used PCR on sorted chromosomes to localize seed storage protein genes in field bean. In order to overcome difficulties of discriminating single chromosome types, they sorted 

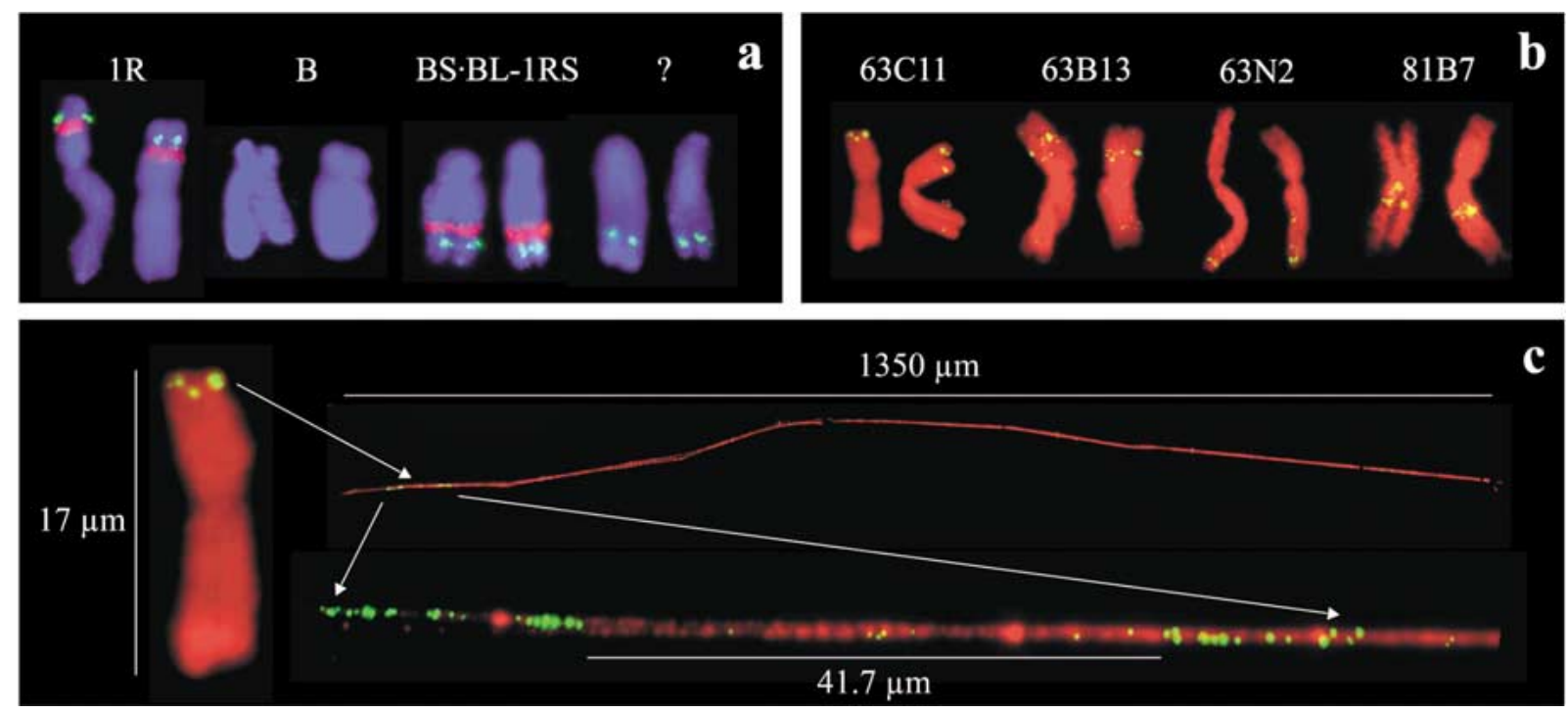

Figure 3. Physical mapping of DNA sequences on flow-sorted chromosomes using FISH. DAPI counterstain is shown in blue (a) and red pseudocolour (b, c). (a) Discovery of two rare translocations between A and B chromosomes in rye (Secale cereale). Flow-sorted rye chromosomes $1 \mathrm{R}$, B chromosomes, and two translocation chromosomes were used for FISH with probes for 45S rDNA (red colour) and 5S rDNA (yellow colour). Two examples are shown for each chromosome and demonstrate the presence of the rDNA loci on $1 \mathrm{R}$ and their absence on the $\mathrm{B}$ chromosome. A translocation between a $\mathrm{B}$ chromosome and short arm of a rye chromosome 1R (BS BL-1RS) could be identified based on the presence of both 45S and 5S rDNA. Using the rDNA probes, it was not possible to decide whether 5S rDNA bearing chromosome 1R or 5R was involved in a second translocation (marked by?) (Kubaláková et al. 2003a). (b) Localization of BAC clones on flow-sorted chromosome 3B of wheat (Triticum aestivum) using FISH; the four BAC clones (63C11, 63B13, 63N2, and 81B7) provide specific chromosome landmarks (yellow signals). For each probe, two representative examples are given (Šafár et al. 2003). (c) The use of super-stretched chromosomes for high-resolution cytogenetic mapping. FISH with a wheat BAC clone $63 \mathrm{C} 11$ detects two sites on each chromatid separated by $0.2 \mu \mathrm{m}$ on the untreated chromosome (17 $\mu \mathrm{m}$ long). The distance increases to $41.7 \mu \mathrm{m}$ on a chromosome that has been stretched to $1350 \mu \mathrm{m}$, resulting in significant improvement in spatial resolution of the region of interest (Valárik et al. 2003).

chromosomes from translocation lines. This permitted gene mapping at the subchromosomal level and integration of genetic and physical maps (Macas et al. 1993, Vaz Patto et al. 1999). Lysák et al. (1999) used the same approach to localize two RFLP probes to regions of two chromosomes of barley. PCR on flow-sorted chromosomes was also used by Kejnovský et al. (2001) to localize male-specifically-expressed MROS genes on sex chromosomes and autosomes of a dioecious plant, white campion (Silene latifolia), and by Vláčilová et al. (2002), who were the first to assign a genetic linkage group to a specific chromosome in chickpea. Although the garden pea has been the object of genetic studies since Gregor Mendel, the assignment of two genetic linkage groups to specific chromosomes remained unclear until Neumann et al. (2002) used flowsorted pea chromosomes for PCR detection of molecular markers selected from these unassigned groups. This elegant work marked the completion of efforts to integrate genetic and physical maps of the pea (Figure 4).

Flow-sorted chromosomes have been used not only for physical mapping of molecular markers but also for the development of markers for mapping. This approach is especially attractive for saturating genetic maps in the regions harbouring agronomically important traits. Arumuganathan et al. (1994) developed eleven RFLP markers from tomato chromosome 2. Macas et al. (1996) and Kobližková et al. (1998) showed that libraries constructed from flow-sorted chromosomes contain microsatellite sequences, and that the libraries can be efficiently enriched for these loci to facilitate their screening for microsatellite markers. More recently, Požárková et al. (2002) developed microsatellite markers from chromosome 1 of 

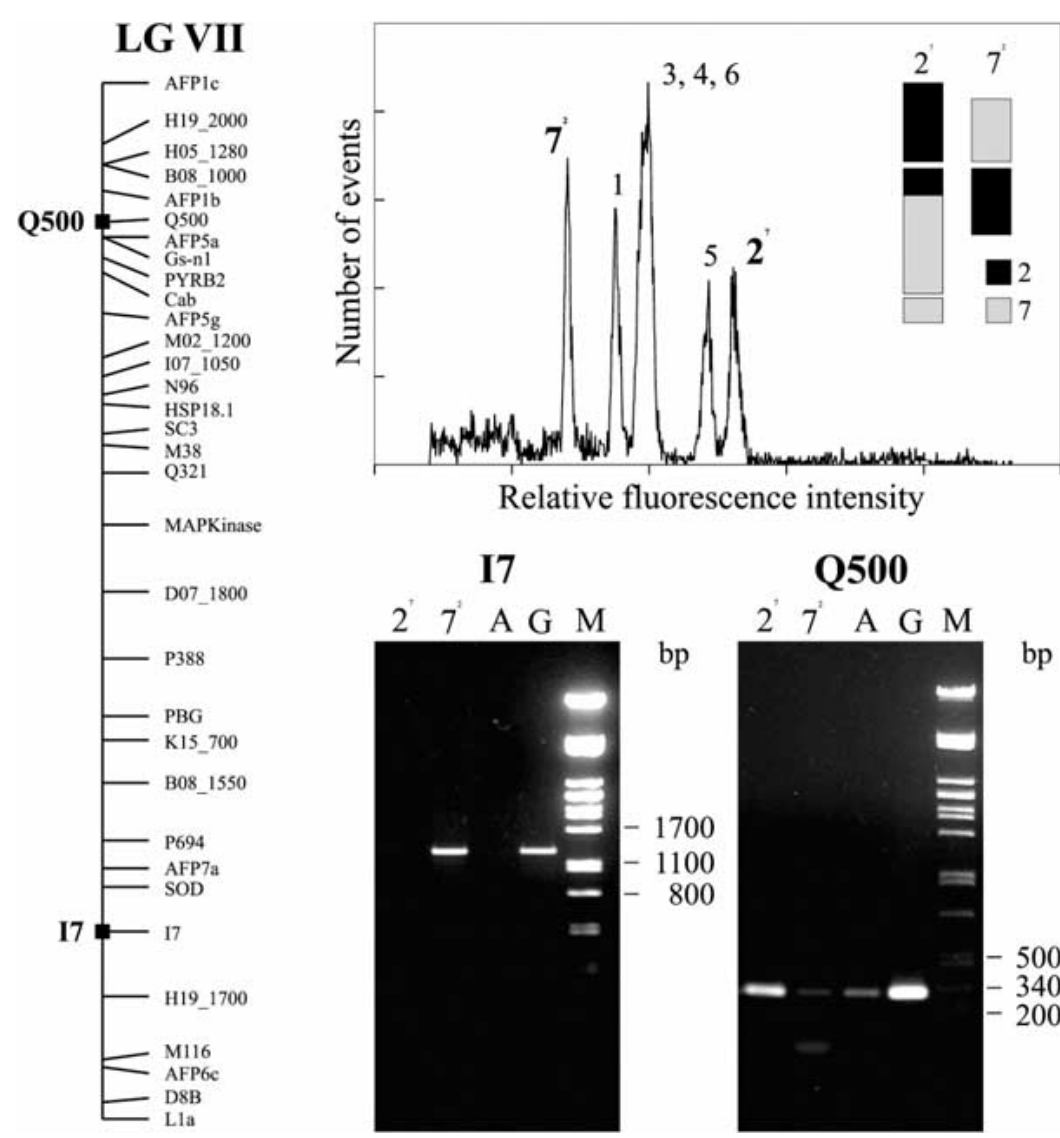

Relative fluorescence intensity

I7

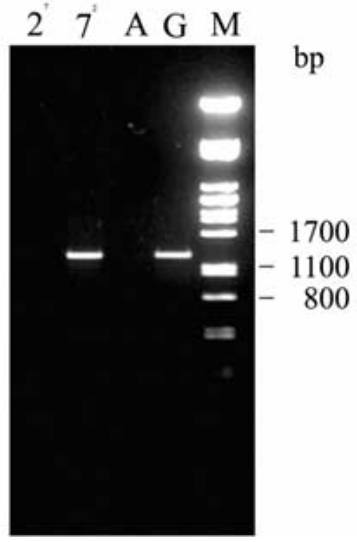

Q500
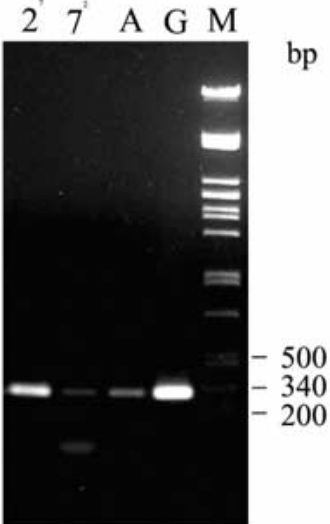

Figure 4. Physical mapping and assignment of a genetic linkage group to a specific chromosome in garden pea (Pisum sativum, $2 n=14$ ). Molecular markers I7 and Q500 were selected from linkage group LG VII, which was thought to be located on either chromosome 4 or 7 . The linkage group was unquestionably mapped to chromosome 7 using PCR on 300 translocation chromosomes $2^{7}, 7^{2}$, and on 1500 chromosomes of the remaining types (lanes A) flow-sorted from a translocation line JI148. PCR products were resolved using agarose gel electrophoresis. Lanes G: total genomic DNA; lanes M: lambda DNA digested with PstI used as a marker. Note that the use of translocation chromosomes facilitated mapping of markers to subchromosomal regions (Neumann et al. 2002, modified).

field bean. This chromosome is the largest in the karyotype and trisomic lines, which have been used for genetic mapping in this crop (Vaz Patto et al. 1999), are not available for chromosome 1. In their work, Požárková et al. (2002) used flowsorted fractions not only to develop the markers but also to confirm their chromosome specificity, thus highlighting the effectiveness of the experimental system. Both Arumuganathan et al. (1994) and Požárková et al. (2002) selected markers from short-insert chromosome-specific DNA libraries.

The utility of DNA libraries depends on the size of inserts, genome coverage, and contamination with unwanted sequences. In contrast to whole genome libraries, chromosome-specific libraries represent defined genome fractions and their use simplifies the analysis of large genomes. The first DNA library prepared using flowsorted plant chromosomes was prepared by Wang et al. (1992). Although the identity of sorted wheat chromosomes could not be verified, half of the unique and low-copy clones selected from the library detected sequences on wheat chromosome 4A. To overcome the need for sorting large numbers of chromosomes required for direct cloning, Arumuganathan et al. (1994) and Požárková et al. (2002) employed DOP-PCR amplification to increase the amount of DNA prior to cloning. As a result of this, the libraries 
had insert sizes in the range of $10^{2}-10^{3} \mathrm{bp}$. Following the same approach, Macas et al. (1996) were the first to prepare a complete set of chromosome-specific libraries covering the whole genome of the field bean. So far, the field bean is the only plant species whose genome is available in the form of chromosome-specific DNA libraries.

Although the short insert DNA libraries are useful tools, libraries with large $\left(\sim 10^{5} \mathrm{bp}\right)$ inserts (e.g. cloned in a BAC vector) are more important as they facilitate construction of physical maps and gene cloning, and are a source of material for other studies and techniques, such as BAC FISH (Figure 3b). Their construction from sorted chromosomes has been hampered by a need for large quantities of high-molecularweight DNA. In 2000, two groups reported recovery of high-molecular-weight DNA from plant chromosomes. Li \& Arumuganathan (2000) obtained DNA over $120 \mathrm{~kb}$ in size from sorted maize chromosomes, and Vrána et al. (2000) showed that majority of DNA obtained from flow-sorted wheat chromosomes was megabase sized (Figure 5). Subsequently, Šimková et al. (2003) developed a protocol for preparation of high-molecular-weight DNA from sorted plant chromosomes. DNA thus obtained was fully digestible by restriction enzymes and suitable for cloning. This progress facilitated construction of a subgenomic BAC library from wheat chromosomes 1D, 4D and 6D (Janda et al. in preparation) and the first ever chromosomespecific BAC library from wheat chromosome 3B (Šafář et al. 2003). The most recent results from Janda et al. (in preparation) demonstrate the possibility of preparing a BAC library specific for a chromosome arm after sorting the wheat telocentric chromosome 1BS from a ditelosomic line.

\section{Limitations and comparison with other methods}

In addition to flow cytometry, microdissection has been used to isolate plant chromosomes. Each method has advantages and disadvantages and both appear to be surprisingly compatible. While any chromosome or chromosome segment may be isolated using microdissection at $100 \%$

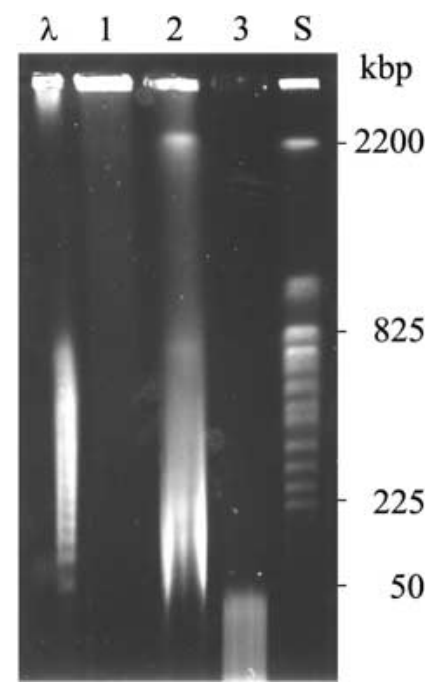

Figure 5. Analysis of the quality of the DNA obtained from flow-sorted chromosomes of wheat (Triticum aestivum). Agarose plugs containing chromosomal DNA were incubated in HindIII buffer containing 0 (lane 1), 5 (lane 2) or 25 units (lane 3) of HindIII restriction enzyme for 5 min (lanes 1 and 2) and $2 \mathrm{~h}$ (lane 3) at $37^{\circ} \mathrm{C}$ and analysed using pulse field gel electrophoresis. Untreated DNA remained in the well (lane 1) suggesting that DNA of sorted chromosomes was intact and of megabase size. At the same time, the DNA was easily accessible to the restriction endonuclease (lanes 2, 3). Lane $\lambda$ : lambda ladder; lane S: chromosomes of Saccharomyces cerevisiae used as size markers (Vrána et al. 2000, modified).

purity, flow sorting relies on intrinsic differences in chromosome size and on the use of specific stocks; the purity is usually less than $100 \%$. Only a very small number of chromosomes may be isolated by microdissection and any work requiring larger amounts of DNA must involve PCR amplification, which results in a collection of short DNA fragments, and which may introduce a bias (Telenius et al. 1992, Macas et al. 1996). Flow cytometry purifies large numbers of chromosomes and high-molecular-weight DNA may be obtained. The possibility of sorting large numbers of chromosomes allows the preparation of many fractions for high-throughput analysis using PCR, and for microscopic analysis. Unlike microdissected chromosomes, flow-sorted chromosomes are suitable for both protein immunolocalization and isolation. Although the currently used protocols for chromosome isolation may easily be modified for other species, their optimization is laborious and time-consuming. One 
may therefore envisage flow cytogenetics being used with a limited number of species of important scientific (e.g., evolution of sex chromosomes) or economic (e.g., gene mapping and isolation) interest. A need for special stocks to discriminate specific chromosomes will also limit the number of species where flow cytogenetics could be used.

\section{Future directions}

Chromosome-mediated gene transfer was probably the first motivation for chromosome sorting in plants (de Laat \& Blaas 1984). Although it is very attractive for both the transfer and mapping of polygenic traits, this goal has not yet been attained. Flow sorting may also aid in preparation of artificial plant chromosomes in significant quantities, as has been shown in humans (de Jong $\mathrm{G}$ et al. 1999). The use of large numbers of mitotic chromosomes for proteomic characterization of chromatin is another avenue to explore. Due to the use of highly purified chromosome fractions, this high-throughput approach has the potential for identifying less abundant and hitherto unknown proteins specific to mitotic chromosomes.

The applications of sorted chromosomes for targeted isolation of molecular markers and for rapid physical mapping using PCR are especially attractive for analysis of complex genomes, which are typical of major legume and cereal crops. As the methods are available for many of these species (Table 1), one may foresee their large-scale use. In addition to PCR screening, hybridization to DNA arrays offers a route to high-throughput physical mapping of various DNA sequences, including expressed sequence tags (ESTs). As huge numbers of ESTs have been generated (Mayer \& Mewes 2002), this may be an attractive approach to facilitating their assignment to individual chromosomes and their parts. HAPPY mapping is an in-vitro technique, which defines the order and spacing of DNA markers directly on native genomic DNA. It appears to be an attractive alternative to in-vivo genetic and physical mapping and is suitable for preparation of maps of entire plant genomes up to $1000 \mathrm{Mb}$ (Waugh et al. 2002). As the genomes of most crops are much larger, purification of individual chromo- somes and chromosome arms may greatly expand the usefulness of HAPPY mapping in plants.

Dissection of a genome into single chromosomes and arms should facilitate analysis of sequence organization and evolution of repetitive DNA sequences (such as telomeric and subtelomeric tandem repeats) at the chromosomal and subchromosomal levels. As thousands of chromosomes may be analysed microscopically on a single slide, there are several potential applications of sorted chromosomes in the area of molecular cytogenetics. These could include highresolution mapping of DNA sequences, analysis of polymorphism of DNA repeats, and discovery of rare structural chromosome changes. The application of super-stretched chromosomes may fill the gap in spatial resolution and sensitivity between FISH on pachytene chromosomes and FISH on DNA fibres. Preparation of chromosome painting probes directly from sorted plant chromosomes seems unlikely. However, if a sufficient number of ESTs is collected, e.g., by hybridization of labelled DNA from sorted chromosomes to DNA arrays, selected ESTs could be pooled to prepare complex chromosomespecific probes.

The recent success in the creation of chromosome- and chromosome-arm-specific BAC libraries represents a great leap forward, and marks the integration of plant flow cytogenetics with genomics. Although genomic BAC libraries exist for most of the important crops, their maintenance and screening may be laborious and costly. A BAC library containing 5.1 genome equivalents of tetraploid wheat consists of 516096 clones (Cenci et al. 2003). In contrast, the BAC library specific for a single wheat chromosome, 3B, with a higher genome coverage $(6.2 \times)$ consists of only 67968 clones (Šafár et al. 2003). Dissection of complex genomes into chromosome- and chromosome-arm-specific BAC libraries is now feasible and should greatly facilitate the study of genome organization, mapbased cloning, physical mapping and genome sequencing.

\section{Acknowledgements}

We are grateful to Ms. Radka Tušková and Jitka Weiserová, Bc. for excellent technical assistance. 
This work was supported by research grants 521/ $03 / 0595$ and 522/03/0354 from the Grant Agency of the Czech Republic, QC1336 from the Ministry of Agriculture of the Czech Republic, and ME527 and ME528 from the Ministry of Education, Youth and Sports of the Czech Republic.

\section{References}

Arumuganathan K, Slattery JP, Tanksley SD, Earle ED (1991) Preparation and flow cytometric analysis of metaphase chromosomes of tomato. Theor Appl Genet 82: 101-111.

Arumuganathan K, Martin GB, Telenius H, Tanksley SD, Earle ED (1994) Chromosome 2-specific DNA clones from flow-sorted chromosomes of tomato. Mol Gen Genet 242: 551-558.

Binarová P, Hause B, Doležel J, Dráber P (1998) Association of $\gamma$-tubulin with kinetochore/centromeric region of plant chromosomes. Plant J 14: 751-757.

Boschman GA, Manders EMM, Rens W, Slater R, Aten JA (1992) Semi-automated detection of aberrant chromosomes in bivariate flow karyotypes. Cytometry 13: 469-477.

Carrano AV, Gray JW, Langlois RG, Yu LC (1983) Flow cytogenetics: Methodology and applications. In: Rowley JD, Ultmann JE, eds. Chromosomes and Cancer. New York: Academic Press, Inc., pp 195-209.

Cenci A, Chantret N, Kong X et al. (2003) Construction and characterization of a half million clone BAC library of durum wheat (Triticum turgidum ssp. durum). Theor Appl Genet 107: 931-939.

Conia J, Bergounioux C, Perennes C, Muller P, Brown S, Gadal P (1987) Flow cytometric analysis and sorting of plant chromosomes from Petunia hybrida protoplasts. Cytometry 8: 500-508.

Conia J, Muller P, Brown S, Bergounioux C, Gadal P (1989) Monoparametric models of flow cytometric karyotypes with spreadsheet software. Theor Appl Genet 77: 295-303.

Cremer T, Lichter P, Borden J, Ward DC, Manuelidis L (1988) Detection of chromosome aberrations in metaphase and interphase tumor cells by in situ hybridisation using chromosome specific library probes. Hum Genet 80: 235-246.

de Jong G, Telenius AH, Telenius H, Perez CF, Drayer JI, Hadlaczky G (1999) Mammalian artificial chromosome pilot facility: Large-scale isolation of functional satellite DNAbased artificial chromosomes. Cytometry 35: 129-133.

de Jong JH, Fransz P, Zabel P (1999) High resolution FISH in plants - techniques and applications. Trends Plant Sci 4: 258-263.

de Laat AMM, Blaas J (1984) Flow-cytometric characterization and sorting of plant chromosomes. Theor Appl Genet 67: 463-467.

de Laat AMM, Schel JHN (1986) The integrity of metaphase chromosomes of Haplopappus gracilis (Nutt.) Gray isolated by flow cytometry. Plant Sci 47: 145-151.

Doležel J (1991) KARYOSTAR: Microcomputer program for modelling of monoparametric flow karyotypes. Biológia 46: 1059-1064.
Doležel J, Lucretti S (1995) High-resolution flow karyotyping and chromosome sorting in Vicia faba lines with standard and reconstructed karyotypes. Theor Appl Genet 90: 797-802.

Doležel J, Binarová P, Lucretti S (1989) Analysis of nuclear DNA content in plant cells by flow cytometry. Biol Plant 31 : 113-120.

Doležel J, Č́ihalíková J, Lucretti S (1992) A high-yield procedure for isolation of metaphase chromosomes from root tips of Vicia faba L. Planta 188: 93-98.

Doležel J, Lucretti S, Schubert I (1994) Plant chromosome analysis and sorting by flow cytometry. Crit Rev Plant Sci 21: 275-309.

Doležel J, Č́́halíková J, Weiserová J, Lucretti S (1999a) Cell cycle synchronization in plant root meristems. Meth Cell Sci 21: 95-107.

Doležel J, Macas J, Lucretti S (1999b) Flow analysis and sorting of plant chromosomes. In: Robinson JP, Darzynkiewicz Z, Dean PN et al., eds. Current Protocols in Cytometry. New York: John Wiley and Sons, Inc., pp 5.3.1.-5.3.33.

Doležel J, Lysák MA, Kubaláková M, Šimková H, Macas J, Lucretti S (2001) Sorting of plant chromosomes. In: Darzynkiewicz Z, Crissman HA, Robinson JP, eds. Flow Cytometry, 3rd Edition, Part B. San Diego: Academic Press, pp 3-31.

Eriksson T (1966) Partial synchronization of cell division in suspension cultures of Haplopappus gracilis. Physiol Plant 19: $900-910$

Gill KS, Arumuganathan K, Le JH (1999) Isolating individual wheat (Triticum aestivum) chromosome arm by flow cytometric analysis of ditelosomic lines. Theor Appl Genet 98: $1248-1252$.

Givan AL (2001) Principles of flow cytometry: an overview. In: Darzynkiewicz Z, Crissman HA, Robinson JP, eds. Flow Cytometry, 3rd Edition, Part A. San Diego: Academic Press, pp 19-50.

Gray JW, Cram LS (1990) Flow karyotyping and chromosome sorting. In: Melamed MR, Lindmo T, Mendelsohn ML, eds. Flow Cytometry and Sorting, Second Edition. New York: Wiley-Liss, pp 503-529.

Grunwald D, Frelat G, Vaiman M (1989) Animal flow cytogenetics. In: Yen A, ed. Flow Cytometry: Advanced Research and Clinical Applications, Vol. 1. Boca Raton: CRC Press, Inc., pp 132-140.

Gualberti G, Doležel J, Macas J, Lucretti S (1996) Preparation of pea (Pisum sativum L.) chromosome and nucleus suspensions from single root tips. Theor Appl Genet 92: 744-751.

Kejnovskỳ E, Vrána J, Matsunaga S et al. (2001) Localization of male-specifically expressed MROS genes of Silene latifolia by PCR on flow-sorted sex chromosomes and autosomes. Genetics 158: 1269-1277.

Kobližková A, Doležel J, Macas J (1998) Subtraction with 3' modified oligonucleotides eliminates amplification artifacts in DNA libraries enriched for microsatellites. BioTechniques 25: 32-38.

Kubalák ková M, Lysák MA, Vrána J, Šimková H, Č́halíková J, Doležel J (2000) Rapid identification and determination of purity of flow-sorted plant chromosomes using C-PRINS. Cytometry 41: 102-108. 
Kubaláková M, Vrána J, Č́íhalíková J, Šmková H, Doležel J (2002) Flow karyotyping and chromosome sorting in bread wheat (Triticum aestivum L.). Theor Appl Genet 104: 1362-1372.

Kubaláková M, Valárik M, Bartoš J et al. (2003a) Analysis and sorting of rye (Secale cereale L.) chromosomes using flow cytometry. Genome 46: 893-905.

Kubaláková M, Bartoš J, Kovářová $\mathrm{P}$ et al. (2003b) Chromosome analysis and sorting in durum wheat and physical mapping of repetitive DNA sequences. In: Proceedings of the Tenth International Wheat Genetics Symposium. Istituto Sperimentale per la Cerealicoltura, Paestum (in press).

Lee JH, Arumuganathan K (1999) Metaphase chromosome accumulation and flow karyotypes in rice (Oryza sativa $\mathrm{L}$.) root tip meristem cells. Mol Cells 9: 436-439.

Lee JH, Arumuganathan K, Kaeppler SM, Kaeppler HF, Papa CM (1996) Cell synchronization and isolation of metaphase chromosomes from maize (Zea mays L.) root tips for flow cytometric analysis and sorting. Genome 39: 697-703.

Lee JH, Arumuganathan K, Yen Y, Kaeppler S, Kaeppler H, Baenziger PS (1997) Root tip cell cycle synchronization and metaphase-chromosome isolation suitable for flow sorting in common wheat (Triticum aestivum L.). Genome 40: 633-638.

Lee JH, Arumuganathan K, Chung YS et al. (2000) Flow cytometric analysis and chromosome sorting of barley (Hordeum vulgare L.). Mol Cells 10: 619-625.

Lee JH, Arumuganathan K, Kaeppler SM et al. (2002) Variability of chromosomal DNA contents in maize ( $\mathrm{Zea}$ mays L.) inbred and hybrid lines. Planta 215: 666-671.

Leitch AR, Schwarzacher T, Wang ML et al. (1993) Molecular cytogenetic analysis of repeated sequences in a long-term wheat-suspension culture. Plant Cell Tissue Org Cult 33: 287-296.

Li L, Arumuganathan K (2000) High recovery of large molecular weight DNA from sorted maize chromosomes. Plant Mol Biol Rep 18: 41-45.

Li LJ, Arumuganathan K, Rines HW et al. (2001) Flow cytometric sorting of maize chromosome 9 from an oatmaize chromosome addition line. Theor Appl Genet 102: 658-663.

Lucretti S, Doležel J (1997) Bivariate flow karyotyping in broad bean (Vicia faba). Cytometry 28: 236-242.

Lucretti S, Doležel J, Schubert I, Fuchs J (1993) Flow karyotyping and sorting of Vicia faba chromosomes. Theor Appl Genet 85: 665-672.

Lysák MA, Číhalíková J, Kubaláková M, Šimková H, Künzel G, Doležel J (1999) Flow karyotyping and sorting of mitotic chromosomes of barley (Hordeum vulgare L.). Chromosome Res 7: 431-444.

Macas J, Doležel J, Lucretti S et al. (1993) Localization of seed protein genes on flow-sorted field bean chromosomes. Chromosome Res 1: 107-115.

Macas J, Doležel J, Gualberti G, Pich U, Schubert I, Lucretti S (1995) Primer-induced labeling of pea and field bean chromosomes in situ and in suspension. BioTechniques 19: 402-408.

Macas J, Gualberti G, Nouzová M, Samec P, Lucretti S, Doležel J (1996) Construction of chromosome-specific DNA libraries covering the whole genome of field bean (Vicia faba L.). Chromosome Res 4: 531-539.

Mayer K, Mewes HW (2002) How can we deliver the large plant genomes? Strategies and perspectives. Curr Opin Plant Biol 5: 173-177.

Neumann P, Lysák M, Doležel J, Macas J (1998) Isolation of chromosomes from Pisum sativum L. hairy root cultures and their analysis by flow cytometry. Plant Sci 137: 205-215.

Neumann P, Požárková D, Vrána J, Doležel J, Macas J (2002) Chromosome sorting and PCR-based physical mapping in pea (Pisum sativum L.). Chromosome Res 10: 63-71.

Pich U, Meister A, Macas J, Doležel J, Lucretti S, Schubert I (1995) Primed in situ labelling facilitates flow sorting of similar sized chromosomes. Plant J 7: 1039-1044.

Pinkel D, Landegent J, Collins C et al. (1988) Fluorescence in situ hybridization with human chromosome-specific libraries. Detection of trisomy 21 and translocations of chromosome 4. Proc Natl Acad Sci USA 85: 9138-9142.

Požárková D, Koblížková A, Román B et al. (2002) Development and characterization of microsatellite markers from chromosome 1-specific DNA libraries of Vicia faba. Biol Plant 45: 337-345.

Šafár J, Janda J, Bartoš J et al. (2003) Dissecting the complex genome of wheat: construction of a chromosome-specific BAC library. Genome Res (submitted).

Schubert I, Doležel J, Houben A, Scherthan H, Wanner G (1993) Refined examination of plant metaphase chromosome structure at different levels made feasible by new isolation methods. Chromosoma 102: 96-101.

Schubert I, Fransz PF, Fuchs J, de Jong H (2003) Chromosome painting in plants. Meth Cell Sci 23: 57-69.

Schwarzacher T, Wang ML, Leitch AR, Miller N, Moore G, Heslop-Harrison JS (1997) Flow cytometric analysis of the chromosomes and stability of a wheat cell-culture line. Theor Appl Genet 94: 91-97.

Śmková H, Č́íhalíková J, Vrána J, Lysák MA, Doležel J (2003) Preparation of high molecular weight DNA from plant nuclei and chromosomes isolated from root tips. Biol Plantarum 46: 369-373

Telenius H, Carter NP, Bebb, CE., Nordenskjöld M, Ponder BAJ, Tunnacliffe A (1992). Degenerate oligonucleotideprimed PCR: general amplification of target DNA by a single degenerate primer. Genomics 13: 718-725.

ten Hoopen R, Manteuffel R, Doležel J, Malysheva L, Schubert I (2000) Evolutionary conservation of kinetochore protein sequences in plants. Chromosoma 109: 482-489.

Überall I, Vrána J, Bartoš J, Šmerda J, Doležel J, Havel L (2003) Isolation of chromosomes from Picea abies L. and their analysis by flow cytometry. Biol Plant (in press).

Valárik M, Bartoš J, Kováŕová P, Kubaláková M, de Jong JH, Doležel J (2003) High-resolution FISH of super-stretched flow sorted plant chromosomes. Plant $J$ (submitted).

Van Dilla MA, Deaven LL, Albright KL et al. (1986) Human chromosome-specific DNA libraries. Construction and availability. Biotechnology 4: 537-552.

Vaz Patto MC, Torres AM, Kobližková A, Macas J, Cubero JI (1999) Development of a genetic composite map of Vicia faba using $\mathrm{F}_{2}$ populations derived from trisomic plants. Theor Appl Genet 98: 736-743 
Veuskens J, Marie D, Brown SC, Jacobs M, Negrutiu I (1995) Flow sorting of the $\mathrm{Y}$ sex-chromosome in the dioecious plant Melandrium album. Cytometry 21: 363-373.

Vláčilová K, Ohri D, Vrána J et al. (2002) Development of flow cytogenetics and physical genome mapping in chickpea (Cicer arietinum L.). Chromosome Res 10: 695-706.

Vrána J, Kubaláková M, Simková H, Č́ihalíková J, Lysák MA, Doležel J (2000) Flow-sorting of mitotic chromosomes in common wheat (Triticum aestivum L). Genetics 156: 2033-2041.
Wang ML, Leitch AR, Schwarzacher T, Heslop-Harrison JS, Moore G (1992) Construction of a chromosome-enriched HpaII library from flow-sorted wheat chromosomes. Nulecic Acids Res 20: 1897-1901.

Wanner G, Formanek H, Martin R, Herrmann RG (1991) High resolution scanning electron microscopy of plant chromosomes. Chromosoma 100: 103-109.

Waugh R, Dear PH, Powell W, Machray GC (2002) Physical education - new technologies for mapping plant genomes. Trends Plant Sci 7: 521-523. 